\title{
Modeling and Simulation of $\mathbf{H}$ and $\mathbf{T}$ Shape Capacitive Comb Accelerometer

\author{
${ }^{* 1}$ Anusha Ganta, ${ }^{2}$ Satyanarayana Talam, ${ }^{3}$ Neela .R \\ ${ }^{1,2}$ Department of Electronics and Instrumentation Engineering, Lakireddy Bali Reddy College of Engineering \\ (A), Mylavaram-521230, India. \\ ${ }^{1,3}$ Department of Electrical and Electronics Engineering, Annamalai University, Chidambaram,India-608002. \\ Email: anushagogireddy27@gmail.com,drtsatyam@gmail.com,neelaaueee@gmail.com
}

Received: 22nd December 2019, Accepted: 08th January 2020, Published: 29th February 2020

\begin{abstract}
The paper Presents the modeling and simulation of a highly sensitive three axis Micro Electro Mechanical Systems (MEMS) based H and T shape Capacitive Accelerometer. The MEMS Capacitive Accelerometer Sensor which both capacitance and displacement are the primary sensing characteristics. The differential capacitive accelerometer produces displacement and capacitance due to applied acceleration. The main focus of the work has to improve the displacement sensitivity by changing the diaphragm dimensions with applied input acceleration from $1 \mathrm{~g}$ to $10 \mathrm{~g}$. The $\mathrm{H}$ and $\mathrm{T}$ shape accelerometers has simulated with the parameterized thickness, length, width of the proof mass for better sensitivity.
\end{abstract}

Keywords

Accelerometer, COMSOL Multiphysics, Displacement, H and T Shape, Sensitivity

\section{Introduction}

The market is growing with different applications, MEMS acceleration sensors have many essential part of systems like smartphones, air bag deployment, navigation and aerospace applications. MEMS based Sensors mostly working on either piezo resistive, piezo electric, capacitive sensing [1]. Piezo resistive sensing type accelerometer works on the principle of change in resistance due to applied pressure. This was the primary sensing mechanism technique .The main drawback of this technique is bounded range of working and high reactions to changing temperature [2].Piezo electric sensors have better displacement but the working changes as surrounding temperature is changed [3].Due to this major limitations capacitive sensing type has the better chance with good sensitivity. It can be applied to a wide range of sensors for detecting change of acceleration, pressure and displacement etc. [4]. Capacitive accelerometer has found the low mechanical sensitivity for square and rectangle is $0.00275 \mathrm{~nm} / \mathrm{g}$ and $0.022 \mathrm{~nm} / \mathrm{g}$ respectively [6].Accelerometer is the one of main sensor being developed and use heavily in biomedical and automotive fields for various purpose like health monitoring, air bag control respectively [7]. The accelerometer shows good linearity but low sensitivity in the operating range [8]. In this paper the capacitive accelerometer has simulated with the combination of $\mathrm{H}$ and $\mathrm{T}$ shape Proof mass and these two accelerometers has compared to found which is given the better sensitivity.

Accelerometer Design

The Capacitive accelerometer type is proposed here having a comb structure. The movable proof mass is suspended via springs connected to the anchors. The $\mathrm{H}$ and $\mathrm{T}$ shaped proof mass structures are presented to analyze the mechanical properties of the accelerometer. The $\mathrm{H}$ and $\mathrm{T}$ shapes structures have different spring constants with respect to the dimensions. The two dimensional structure of $\mathrm{H}$ and $\mathrm{T}$ shape is shown in below Fig.1(a) and (b) respectively. The comb accelerometer has a fixed part which is connected to moving part of accelerometer. Initially at zero acceleration is applied on the proof mass, the zero displacement is occurred and equal capacitances $\mathrm{C} 1, \mathrm{C} 2$ has formed with fixed electrodes. When acceleration is applied on the proof mass the displacement is occurred and differential capacitance is formed in between every three electrodes. Higher sensitivity will be formed by the lower spring constant, spring which is connected to proof mass both sides. The dimensions of the $\mathrm{H}$ and $\mathrm{T}$ shape accelerometers are given below. The width of the proof mass is $70 \mu \mathrm{m}$, length is $475 \mu \mathrm{m}$, width of the beam and capacitance gap is $10 \mu \mathrm{m}$, Length of the beams are $220 \mu \mathrm{m}$, Devices Thickness $5 \mu \mathrm{m}$, width of the finger $7 \mu \mathrm{m}$, Length of the fingers $100 \mu \mathrm{m}$, Number of sensing fingers for T shape and $\mathrm{H}$ shape is 72 and 48 respectively. The density of the polycrystalline silicon which is used as a material for proof mass is $5316 \mathrm{~kg} / \mathrm{m} 3$, Proof mass is $7.69 \times 10^{-10}$, the spring constant for T shape is $1.72 \times 10^{12}$ and $\mathrm{H}$ shape is $1.28 \times 10^{8}$, The proof mass for $\mathrm{H}$ shape is $8772 \times 10^{-13} \mathrm{Kg}$ and $\mathrm{T}$ shape is $1993 \times 10^{-13} \mathrm{Kg}$.

\section{Results and Discussion}

The acceleration applied on the proof mass from $1 \mathrm{~g}$ to $10 \mathrm{~g}$, the corresponding displacement for $\mathrm{H}$ and $\mathrm{T}$ shape is shown in below Table1. The corresponding simulation outputs are shown in figure3(a)and (b). 


\begin{tabular}{|l|l|l|}
\hline Acceleration(g) & T-Shape & H-Shape \\
\hline & \multicolumn{2}{|l|}{ Displacement(nm) } \\
\hline 1 & 0.0001 & $4 \mathrm{e}-4$ \\
\hline 2 & 0.0002 & 0.08 \\
\hline 3 & 0.0004 & 0.12 \\
\hline 4 & 0.0005 & 0.16 \\
\hline 5 & 0.06 & 0.2 \\
\hline 6 & 0.07 & 0.24 \\
\hline 7 & 0.08 & 0.28 \\
\hline 8 & 0.1 & 0.32 \\
\hline 9 & 0.11 & 0.36 \\
\hline 10 & 0.12 & 0.4 \\
\hline
\end{tabular}

Table1: Acceleration Vs Displacement

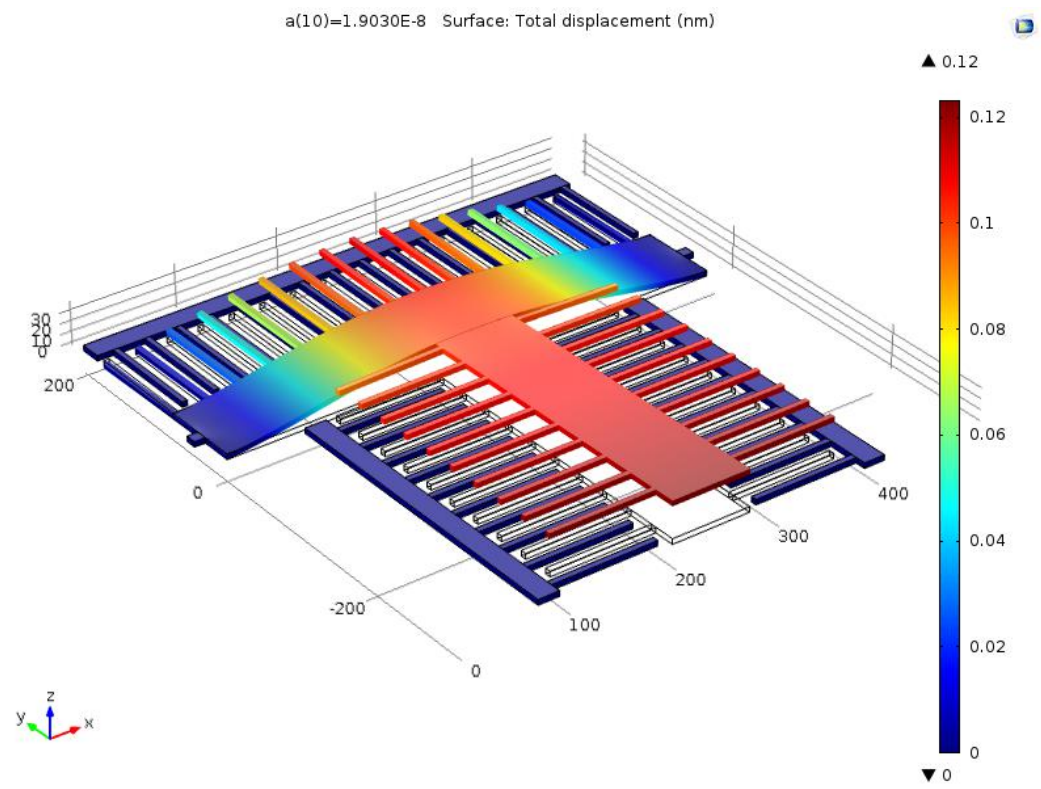

(a) 


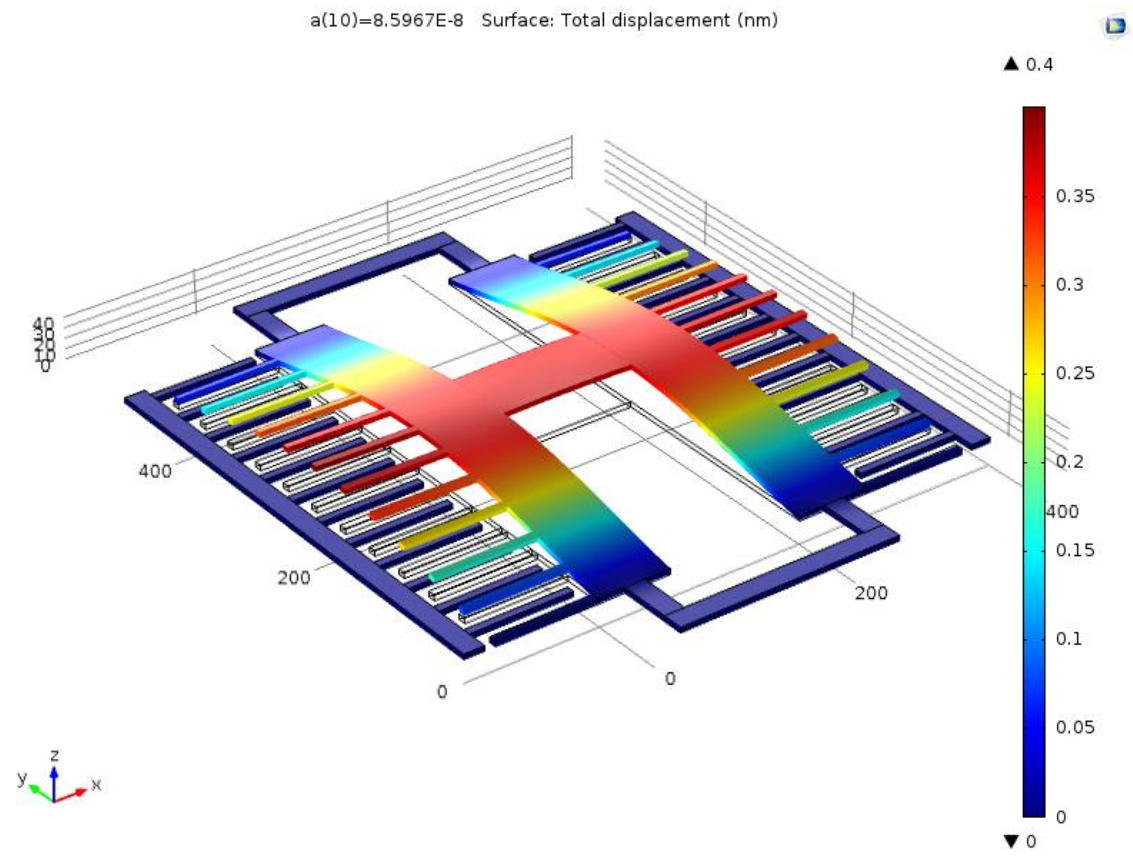

(b)

Fig. 2: (a) \& (b) Displacement at $10 \mathrm{~g} \mathrm{~T}$-shape and $\mathrm{H}$-shape respectively.

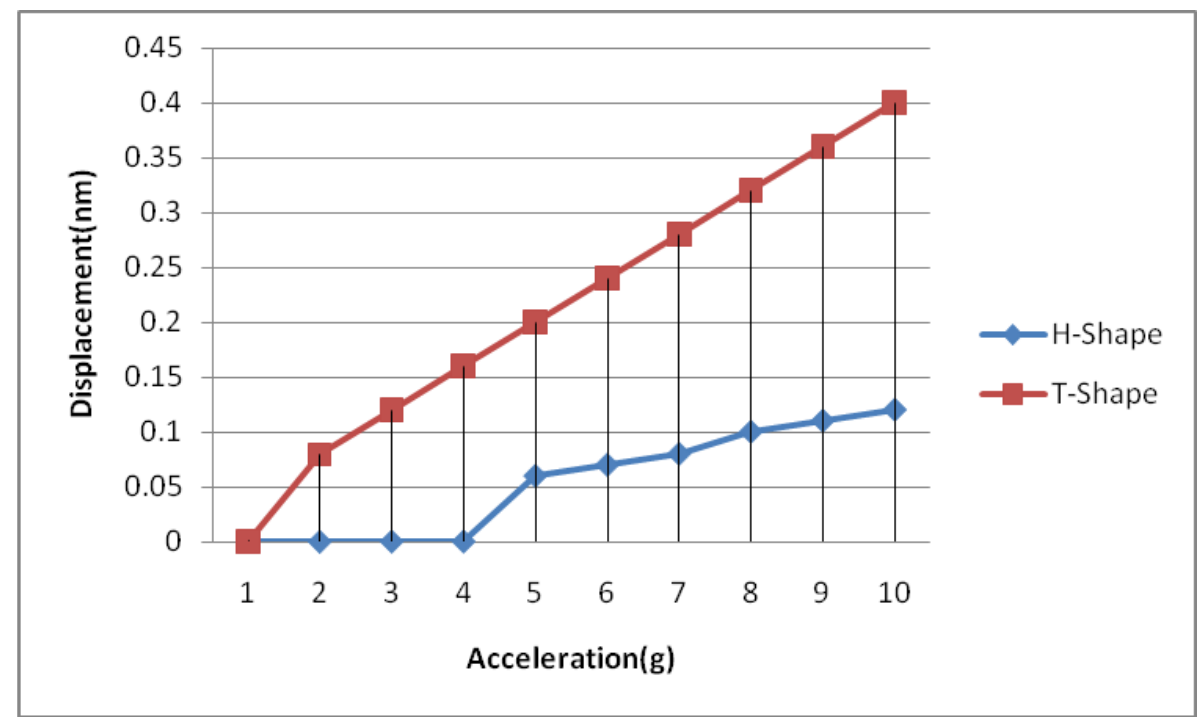

\section{Graph 1: Acceleration (1g to 10g)Vs Displacement}

The displacement has found with respect to the thickness at acceleration $10 \mathrm{~g}$ as shown in below table2.The Thickness of the entire model has varied from 10 to $2 \mu \mathrm{m}$.The displacement is varied from 0.0002 to $1.91 \mathrm{~nm}$ for T-shape, 0.06 to $4.98 \mathrm{~nm}$ for $\mathrm{H}$ - shape w.r.t the thickness 10 to $2 \mu \mathrm{m}$ respectively. The maximum capacitance at $10 \mathrm{~g}$ acceleration with $2 \mu \mathrm{m}$ for $\mathrm{H}$ - shape is $7.03 \mathrm{e}-14 \mathrm{fF}$ and T-Shape is $2.28 \mathrm{e}-13 \mathrm{fF}$. 


\begin{tabular}{|l|l|l|l|l|}
\hline \multirow{2}{*}{ Thickness $(\boldsymbol{\mu m})$} & T-Shape & H-Shape & T-Shape & H-Shape \\
\cline { 2 - 5 } & \multicolumn{2}{|c|}{ Displacement(nm) } & \multicolumn{2}{c|}{ Sensitivity(nm/g) } \\
\hline 10 & 0.0002 & 0.06 & 0.00002 & 0.006 \\
\hline 9 & 0.0002 & 0.1 & 0.00002 & 0.01 \\
\hline 8 & 0.0003 & 0.12 & 0.00003 & 0.012 \\
\hline 7 & 0.0005 & 0.16 & 0.00005 & 0.016 \\
\hline 6 & 0.08 & 0.25 & 0.008 & 0.025 \\
\hline 5 & 0.12 & 0.4 & 0.012 & 0.04 \\
\hline 4 & 0.23 & 0.74 & 0.023 & 0.074 \\
\hline 3 & 0.54 & 1.63 & 0.054 & 0.163 \\
\hline 2 & 1.91 & 4.98 & 0.191 & 0.498 \\
\hline
\end{tabular}

Table 2: Thickness Vs Displacement

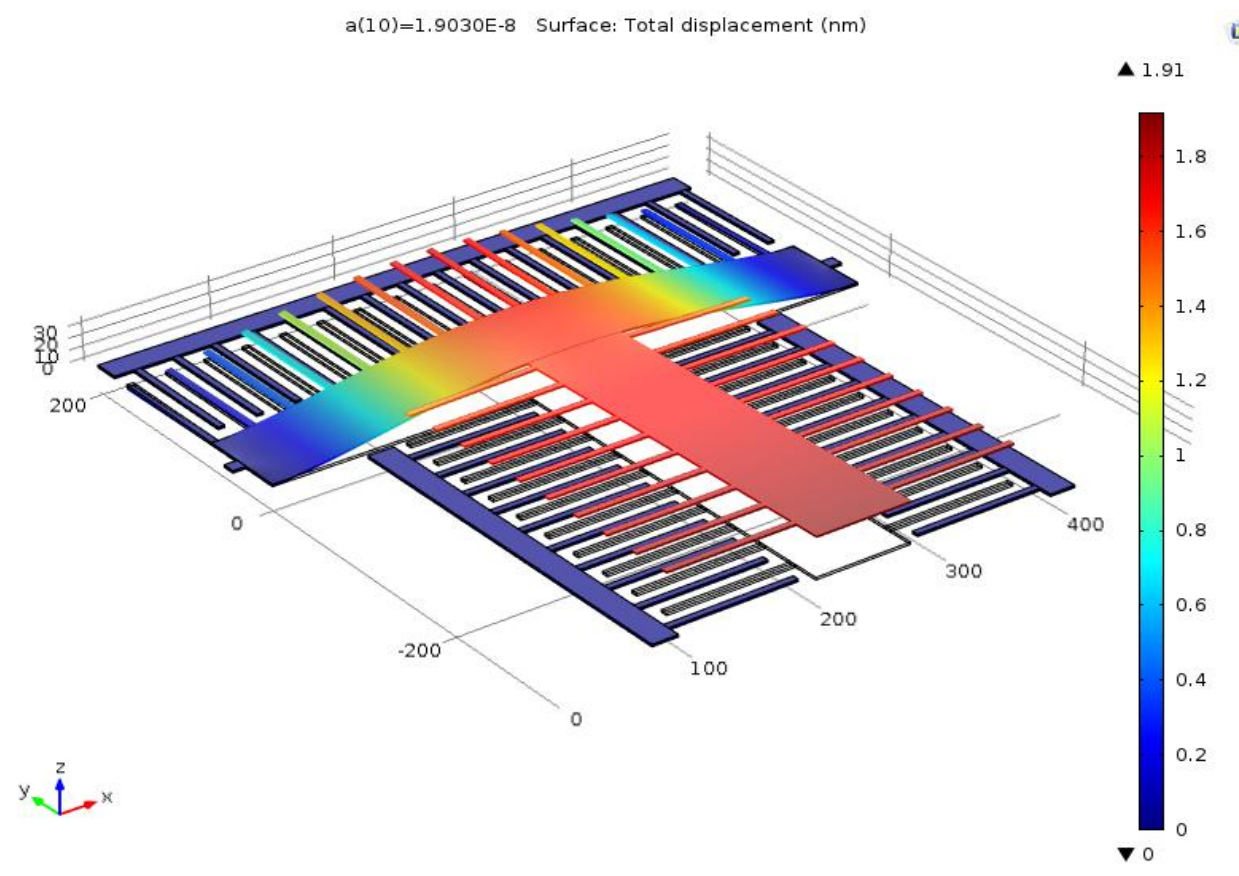

(a) 


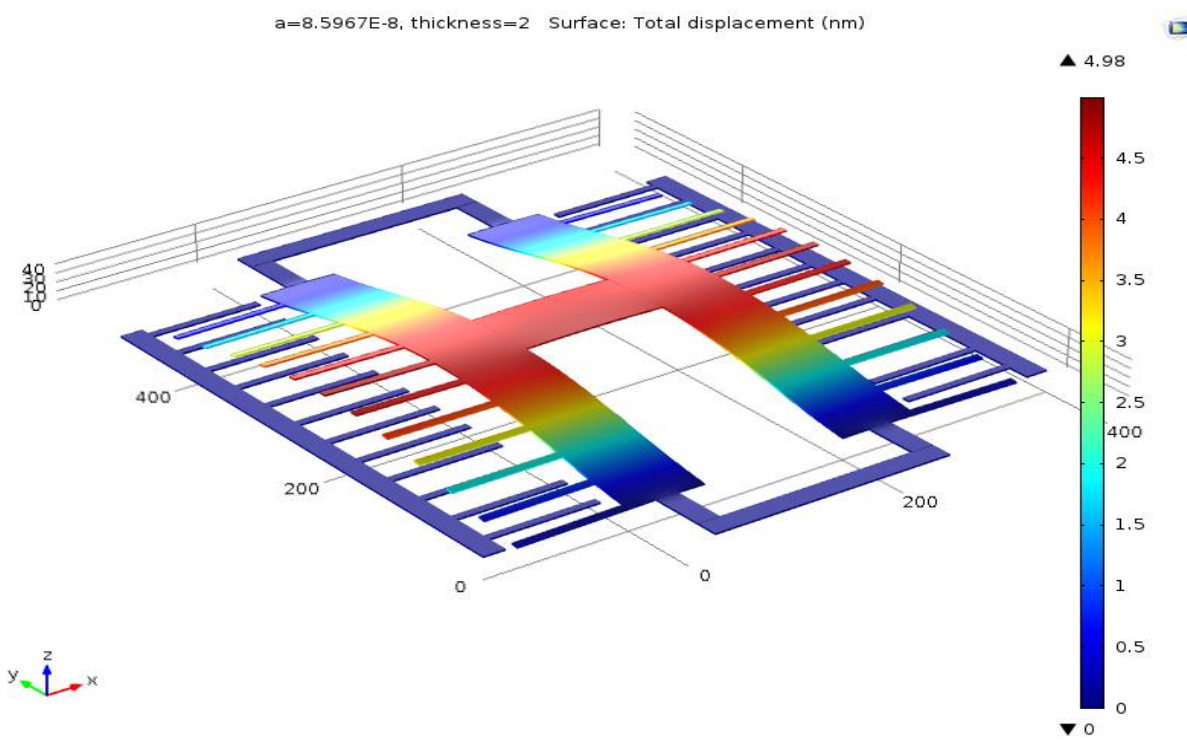

(b)

Fig. 3: (a) \& (b) Displacement at $10 \mathrm{~g}$ with $2 \mu \mathrm{m}$ Thickness T-shape and $\mathrm{H}$-shape respectively.

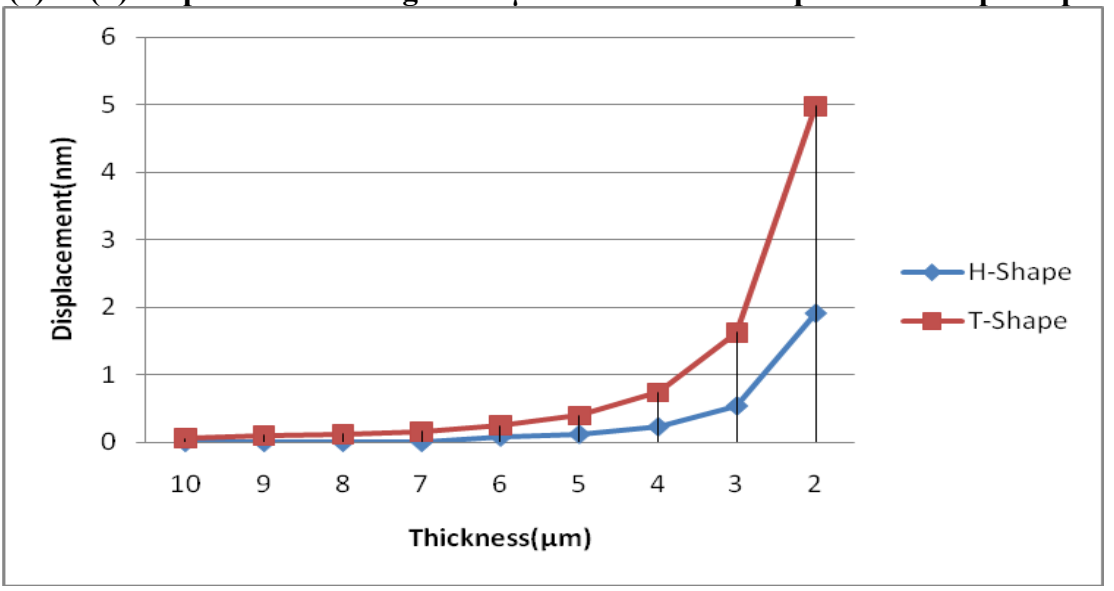

Graph 2: Thickness Vs Displacement at 10g Acceleration

\begin{tabular}{|c|c|c|c|c|}
\hline \multirow{2}{*}{$\begin{array}{l}\text { Length of the } \\
\text { Proof mass } \\
(\mu \mathrm{m})\end{array}$} & $\begin{array}{l}\text { T } \\
\text { Shape }\end{array}$ & $\begin{array}{l}\text { H } \\
\text { Shape }\end{array}$ & $\begin{array}{l}\text { T } \\
\text { Shape }\end{array}$ & $\begin{array}{l}\text { H } \\
\text { Shape }\end{array}$ \\
\hline & \multicolumn{2}{|c|}{$\begin{array}{c}\text { Displacement } \\
\text { (nm) }\end{array}$} & \multicolumn{2}{|c|}{$\begin{array}{c}\text { Sensitivity } \\
(\mathrm{nm} / \mathbf{g})\end{array}$} \\
\hline 500 & 1.7 & 4.55 & 0.17 & 0.455 \\
\hline 600 & 1.41 & 3.96 & 0.141 & 0.396 \\
\hline 700 & 1.85 & 7.3 & 0.185 & 0.73 \\
\hline 800 & 7.43 & 15.1 & 0.743 & 0.151 \\
\hline 900 & 19.8 & 23.8 & 0.198 & 0.238 \\
\hline 1000 & 42.2 & 57.2 & 0.422 & 0.572 \\
\hline
\end{tabular}

Table 3: Length of the Proof mass Vs Displacement 


\begin{tabular}{|c|l|l|l|l|}
\hline $\begin{array}{c}\text { Width of the } \\
\text { Proof mass } \\
(\boldsymbol{\mu} \mathbf{m})\end{array}$ & $\begin{array}{l}\text { T } \\
\text { Shape }\end{array}$ & $\begin{array}{l}\text { H } \\
\text { Shape }\end{array}$ & $\begin{array}{l}\text { T } \\
\text { Shape }\end{array}$ & $\begin{array}{l}\text { H } \\
\text { Shape }\end{array}$ \\
\hline & \multicolumn{2}{|c|}{ Displacement(nm) } & \multicolumn{2}{|c|}{ Sensitivity(nm/g) } \\
\hline 100 & 1.33 & 3.96 & 0.133 & 0.396 \\
\hline 90 & 1.56 & 4.3 & 0.156 & 0.43 \\
\hline 80 & 1.69 & 4.68 & 0.16 & 0.468 \\
\hline 70 & 1.91 & 4.98 & 0.191 & 0.498 \\
\hline 60 & 2.3 & 5.23 & 0.23 & 0.523 \\
\hline 50 & 2.82 & 15.8 & 0.282 & 0.158 \\
\hline 40 & 3.79 & 21.5 & 0.379 & 0.215 \\
\hline 30 & 7.45 & 35.8 & 0.745 & 3.58 \\
\hline
\end{tabular}

Table 4: Width of the Proof mass Vs Displacement

\section{Conclusion}

Most of the parameters in differential capacitive accelerometer like the finger dimensions, the beam dimensions and length of the sensor need to be chosen attentive. The results obtained by varying certain dimensions for better displacement sensitivity and capacitive sensitivity. The dimensions of the differential capacitive accelerometer have one of the major advantage to improve the sensitivity. It is observed that the displacement sensitivity has been improved by changing the beam length, width and thickness. As observed, by decreasing the thickness , width and increasing length practically achieved high sensitivity for a device.

\section{References}

1. F. Levinzon, "Piezoelectric Transducers Used for Piezoelectric Accelerometers with Integral Electronics", Springer, 2015.

2. C.M.Sun, C.W.Wang and W.Fang," On the Sensitivity improvement of CMOS Capacitive accelerometer",Sensors and Actuators A 141,347-352(2008) .

3. L.M.Roylance and J.B.Angell, "A Batch-fabricated silicon accelerometer", IEEE Electron Devices 26,1911-1917.

4. P. Eswaran and S. Malarvizhi, "Design analysis of MEMS capacitive differential pressure sensor for aircraft altimeter”, Int. J. Appl. Phys. Math. 2 (2012) 14-20.

5. Anusha Ganta, Satyanarayana Talam, Neela.R," Modelling and Simulation of MEMS Comb Accelerometer for Sensitivity Improvement" International Journal of Innovative Technology and Exploring Engineering,8(8)(2019),2578-2583.

6. Anusha Ganta,Satyanarayana Talam,Neela.R," Modelling and Simulation of MEMS Comb Accelerometer for Sensitivity Improvement with different Proof mass patterns" International Journal of Engineering and Advanced Technology,8(6)(2019),1665-1660.

7. Sumit Kumat Jintal, Srihsti Priya, S. Kshipra Prasad“ Design Guidelines for MEMS Optical Accelerometer based on Dependence of Sensitivities on Diaphragm Dimensions", Journal of Circuits, Systems and Computers,29(7)(2019),2050107-2050126.

8. R.Mukhiya,P.Agarwal,S.Badjatya,M.Garg,P.Gaikwad,S.Sinha,A.K.Singh,R.Gopal“Design ,Modelling and system level simulation of DRIE based MEMS differential capacitive accelerometer"25(2019),3521-3533.

9. Xiaofeng Zhou, Lufeng Che, Shenglin Liang, Youling Lin, Xiaolin Li, Yuelin Wang "Design and Fabrication of MEMS Capacitive accelerometer with fully Symmetrical double sided H-shaped beam structure", Micro Electronics Engineering(Elsevier)"131(2015)51-57. 